\title{
POLITIKK
}

SKANDINAVISK TIDSSKRIFT

FOR INTERNASJONALE STUDIER

Årgang 78, Nummer 2, side 195-206, 2020, ISSN 1891-1757, www.tidsskriftet-ip.no, Publisert juni 2020

Fokus: Bosnia - 25 År ETTER SEbrenica

\section{Srebrenica 25 år etter - hvordan kunne folkemordet skje?}

\author{
Svein Mønnesland \\ Universitetet $i$ Oslo
}

\begin{abstract}
Sammendrag
Folkemordet i Srebrenica i juli 1995 opprørte en hel verden. Siden 1992, da krigen brøt ut, hadde Bosnia-Hercegovina vært under internasjonalt oppsyn. Artikkelen drøfter hvordan folkemord og grove krigsforbrytelser kunne foregå i årevis uten å bli stanset. Fokus er på den rolle de internasjonale faktorene spilte - FN, EU, Nato og stormaktene. Hvorfor var det så stor motstand mot bruk av makt? Delvis kan det ha vært på grunn av manglende forståelse av hva som skjedde, en oppfatning av at Balkan var preget av århundregammelt hat. Noen vestlige land hadde sine egne interesser i området. For vestlige politikere var det enkleste ikke å gjøre noe. FN sendte fredsbevarende styrker til et land i krig, noe som var katastrofalt for styrkene selv og for FNs prestisje. De tiltakene som ble satt i verk, som Sikkerhetsrådets resolusjoner, økonomiske sanksjoner, våpenembargo, FN-sikrede områder og flyforbud, førte ikke til at krigshandlingene avtok. Også mange norske politikere var sterkt imot militær inngripen. Den serbiske hæren var for sterk, en militær løsning var ikke mulig. Dette viste seg å være feil. Folkemordet i Srebrenica fikk FN og Nato til å gå inn for maktbruk i september 1995. En begrenset militær aksjon var nok til å få slutt på krigen, og reelle fredsforhandlinger kunne begynne.
\end{abstract}

Nøkkelord: Bosnia-Hercegovina $\cdot$ FN $\cdot$ NATO $\cdot$ EU $\cdot$ militær intervensjon

Massakren i Srebrenica i juli 1995 da omkring 8000 menn og gutter ble drept i løpet av noen dager, sjokkerte en hel verden. Mange spurte seg hvordan dette kunne skje i Europa. Srebrenica var kulminasjonen på en fire år lang konflikt. Var krigene i

\footnotetext{
^Kontaktinformasjon: Svein Mønnesland, e-post: sveinmon@ilos.uio.no

(C)2020 Svein Mønnesland. This is an Open Access article distributed under the terms of the Creative Commons Attribution 4.0 International License (http://creativecommons.org/licenses/by/4.0/), allowing third parties to copy and redistribute the material in any medium or format and to remix, transform, and build upon the material for any purpose, even commercially, provided the original work is properly cited and states its license.

Citation: Svein Mønnesland (2020). Srebrenica 25 àr etter - hvordan kunne folkemordet skje? Internasjonal Politikk, 78(2): 195-206. http://dx.doi.org/10.23865/intpol.v78.2317
} 
Kroatia og Bosnia-Hercegovina (1991-1995) uunngåelige? Hva kunne vært gjort for å hindre katastrofen? Hvilke internasjonale aktører var involvert? Hvilke feil gjorde det internasjonale samfunnet?

\section{Den interne utviklingen}

Da det brøt ut krig på Balkan, var Europa ikke forberedt. Kunnskapen om Balkan var begrenset. Det kommunistiske Jugoslavia var et glansbilde som dekket over potensielle konflikter. Men gamle forestillinger om Balkan som Europas kruttønne var levende. Krigene i Kroatia i 1991 og Bosnia-Hercegovina 1992-1995 var imidlertid ikke en følge av «århundregammelt hat», slik noen fremstilte det. Årsaken var kamp om territorier da Jugoslavia gikk i oppløsning og kommunistpartiet mistet makten. Middelet var den jugoslaviske hæren, som ble kontrollert av ekstreme nasjonalister.

I Bosnia-Hercegovina var befolkningen delt mellom bosnjaker (muslimer 43 prosent), serbere (ortodokse 31 prosent) og kroater (katolikker 17 prosent). De snakker samme språk, men har ulik familietradisjon når det gjelder religion. De fleste var ikke aktivt religiøse, men forskjellene avspeiler seg i blant annet fornavn, alfabet og visse tradisjoner, uten at det spilte noen stor rolle. I 1991 var over en fjerdedel «blandede ekteskap», og barna var «bosniere». Lenge var vanlige folk overbevist om at det ikke kunne bli noen innbyrdeskrig $i$ et land hvor folk levde så fredelig sammen. Alt dette forandret seg da politikken ble overtatt av nasjonalister.

Etter president Titos død i 1980 fulgte ti år med økonomisk krise og økende motsetninger mellom Jugoslavias seks delrepublikker. I Serbia innførte Slobodan Milošević fra 1987 en militant sjåvinistisk politikk som skremte politikerne i de andre republikkene. I Slovenia ønsket man å liberalisere systemet og innføre flerpartisystem. Etter kommunismens fall i Øst-Europa høsten 1989 gikk også det jugoslaviske kommunistpartiet i oppløsning, og det var fritt frem for delrepublikkene å velge sin politiske løsning. I 1990 ble det gjennomført flerpartivalg i alle republikkene, og i de fleste var det nasjonalistiske politikere som kom til makten.

Samme år, i 1990, gikk Jugoslavia i oppløsning. Serbia vedtok en grunnlov som i praksis gjorde landet uavhengig. I 1991 valgte Slovenia, Kroatia og Makedonia å bli selvstendige stater. Den serbiske minoriteten i Kroatia startet, med støtte fra Serbia, et opprør for å hindre at de «serbiske områdene» skulle tilhøre Kroatia. Krigen i Kroatia varte fra sommeren 1991 til januar 1992. Byen Vukovar ble det nye Guernica. Første gang spørsmålet om maktbruk kom opp, blant annet i USAs regjering, var da Dubrovnik ble angrepet høsten 1991. Hvis man da hadde vist internasjonal handlekraft, kan det være at katastrofen i Bosnia kunne ha vært unngått. Men vestlige politikere lukket øynene.

Krigen i Kroatia førte til en voldsom eskalering av hatefull propaganda. Nasjonalistisk retorikk (historiske myter, symboler, religiøse forskjeller) ble brukt som våpen, ikke minst i massemediene, kontrollert av politikerne. «De andre» ble fremstilt negativt. I serbisk propaganda ble minnene fra andre verdenskrig gjenopplivet. 
I Bosnia-Hercegovina ønsket flertallet (bosnjakene og kroatene) en selvstendig stat, men serberne kunne bare godta innlemmelse i et rest-Jugoslavia dominert av Serbia. Allerede 9. januar 1992, før krigen brøt ut, utropte de en egen serbisk republikk, en parastat med Radovan Karadžić som president. Dette betydde en oppdeling av landet, men målet var å ta kontroll over det meste og innlemme det i Serbia. Kroatiske nasjonalister ønsket at de kroatisk-befolkede områdene skulle innlemmes i Kroatia og opprettet "Herceg-Bosna», en kroatisk parastat. Bosnia-Hercegovina ble dermed skviset mellom to nasjonalismer. Serberne (Milošević) gjenopplivet den gamle drømmen om stor-Serbia. Kroatene (Tudjman) hadde som mål grensen for Banovina Kroatia fra 1939, som omfattet deler av Bosnia-Hercegovina. Bosnjakene ønsket å opprettholde en samlet stat.

Etter avstemningen om uavhengighet 1. mars 1992, boikottet av serberne, erklærte Bosnia-Hercegovina seg uavhengig, ble anerkjent internasjonalt av mange stater 6. april og ble medlem av FN 22. mai. Den internasjonale anerkjennelsen hindret ikke angrepet, som kom i begynnelsen av april. Serberne hadde kontroll over den jugoslaviske hæren og tok fort kontroll over 70 prosent av landet. I denne perioden, 1992, var det ingen borgerkrig, men en militær og politisk maktovertakelse. De ekstreme serbiske nasjonalistene hadde som mål ikke bare å ta kontroll over territoriet, men at det skulle være "etnisk rent». Den mest effektive måten å «renske» territoriet på var å skremme de andre så ettertrykkelig at de flyktet. Derfor utførte paramilitære styrker fra Serbia massakrer mot sivile i 1992 i byer som Bijeljina, Zvornik og Prijedor. Innen september var det over 1,3 millioner flyktninger, internt og i utlandet.

Hvordan reagerte det internasjonale samfunnet på konflikten? Bildet er komplisert.

\section{Rollen til EF/EU}

EFs linje var å satse på diplomati. Det innebar nøytralitet, ingen av partene skulle kritiseres. Dette var en stor feil. Hadde europeiske stormakter reagert kraftig mot den etniske rensingen, ville det vært vanskeligere for serberne å fortsette. EF ville ikke bruke ord som «konsentrasjonsleirer», selv om de var avslørt av reportere, for ikke å snakke om «massevoldtekt» og «folkemord». Norges linje var å følge EFs politikk.

EF (EU fra 1. september 1993) ble dessuten lammet fordi de ledende statene ikke var enige om hvordan man skulle forholde seg til konflikten. Storbritannia og Frankrike var Serbia-vennlige, mens Tyskland hadde støttet Kroatias uavhengighet. Storbritannia (statsminister John Major) var sterkt imot maktbruk, noe som i realiteten var støtte til den serbiske siden. Storbritannia trodde at serberne raskt ville vinne militært, og at krigen dermed ville bli kortvarig. Da dette viste seg ikke å stemme, ble Storbritannia ledende i fredsarbeidet. Lord Carrington og senere Lord Owen utarbeidet fredsplaner. Carrington la, sammen med FNs Cyrus Vance, frem sin plan i slutten av 1992. Landet skulle deles i ti områder etter etnisk flertall. Men planen er blitt kalt «en diplomatisk katastrofe». Serberne måtte gi fra seg 25 prosent av territoriet de 


\section{Svein Mønnesland}

hadde okkupert, noe de ikke ville. Kroatene, derimot, var lykkelige og begynte å ta kontroll i «sine» områder. Dette førte til konflikt med bosnjakene. «Fredsplanen» var dermed årsak til ny krig. Det alvorligste var likevel at det internasjonale samfunnet nå forhandlet med krigsforbrytere og ga dem legitimitet. Den neste "fredsplanen» fulgte planene til Milošević og Tudjman om en oppdeling av landet, uten å ta hensyn til bosnjakene. Thorvald Stoltenberg, som sammen med Owen la frem planen, kritiserte bosnjakene for ikke å ønske fred. Men en plan som totalt overså den ene parten - og det den som hadde lidd mest - var ikke bærekraftig. Fredsforhandlerne forholdt seg til det militære styrkeforholdet, ikke hva som var rettferdig, og de godtok nasjonalistenes premiss, at flerkulturelt samliv ikke var mulig.

I tillegg til forhandlinger var EUs politikk å sørge for humanitær hjelp. Konvoier og luftbroer holdt befolkningen, særlig bosnjakene, i live, men bidro samtidig til å forlenge krigen. Det ble mer og mer klart at diplomati uten makt bare gjorde at krigen og overgrepene kunne fortsette.

\section{USAs rolle}

I den første perioden var ikke Balkan viktig for USA. President Bush var opptatt på annet hold og overlot konflikten til Europa. Warren Zimmermann, som var amerikansk ambassadør til Jugoslavia frem til mai 1992, hevder: «U.S. air strikes in the summer of 1992 would almost certainly have brought the Serbs to a negotiated settlement and saved tens of thousands of lives.»

Det var først med president Clinton at USA begynte å interessere seg for Balkan. I mai 1993 lanserte Clinton USAs nye politikk, å heve våpenembargoen så bosnjakene kunne få våpen å forsvare seg med, for deretter å true med luftangrep mot serbiske mål. En viktig talsperson for denne linjen, som ble kalt «lift and strike», var USAs FN-ambassadør Madeleine Albright. Men Clinton nølte, blant annet på grunn av konflikt med Frankrike (president Chirac) om i hvilken grad Europa eller USA skulle ha styringen over felles Nato- og EU-styrker (Combined Joint Task Forces).

USA grep imidlertid positivt inn i fredsforhandlingene i Bosnia. Med «Washington-avtalen» i mars 1994 ble det slutt på krigen mellom kroater og bosnjaker. Det skulle likevel ta lang tid før amerikanerne virkelig kom på banen.

\section{FNs rolle}

EUs «nøytralitet» var i realiteten støtte til angriperne. Det var dermed opp til FN å handle, men FNs sikkerhetsråd var splittet og lammet. Sikkerhetsrådet vedtok 67 resolusjoner mellom april 1992 og januar 1995, uten at overgrepene avtok. Allerede i september 1991 hadde $\mathrm{FN}$ vedtatt våpenembargo, men den tjente bare den parten som hadde våpen og produserte nye. De bosniske serberne overtok den bosniske delen av den tidligere Jugoslaviske hæren og fikk militær støtte av Serbia. Bosnjakene fikk våpen smuglet inn, men ikke tyngre våpen, slik at de militært fortsatt var svært underlegne. 
Tidlig i 1992 burde FN ha gått inn med fredsbevarende styrker i Bosnia-Hercegovina. Men i stedet etablerte man hovedkvarter i Sarajevo for å administrere FN-sonene i Kroatia. Det var naivt ikke å se at krigen måtte komme også i Bosnia-Hercegovina.

Det er blitt hevdet at USAs sterke støtte til uavhengighet for Bosnia-Hercegovina var et feilgrep som førte til krig. Det er imidlertid vanskelig å tro at Serbia ikke uansett ville ha annektert store deler av landet med makt og gjennomført den etniske rensingen. Og uten uavhengighet og FN-medlemskap ville bosnjakenes situasjon ha vært mye svakere. En feil var det imidlertid at USA og andre land støttet uavhengighet uten å garantere landets sikkerhet.

I juni 1992 ble FNs fredsbevarende styrker (UNPROFOR), som til da hadde overvåket våpenhvilen i Kroatia, utvidet til å gjelde Bosnia-Hercegovina. FNs generalsekretær Boutros Boutros-Ghali og spesialutsending Yasushi Akashi tolket mandatet som utelukkende fredsbevarende, ikke fredsopprettende. Men begrepet "fredsbevarende styrker» var absurd i et land i krig. FNs rolle ble å beskytte humanitær bistand, men FN-styrkenes situasjon ble uholdbar. De kunne ikke forsvare sivilbefolkningen mot overgrep, ikke engang forsvare seg selv. Passivt måtte de observere at sivile ble drept for øynene deres. FN ble ydmyket. Tidlig i krigen, i januar 1993, ble Bosnias visepresident Turajlić drept av serbiske soldater mens han var på vei fra flyplassen i et pansret FN-kjøretøy, «beskyttet» av franske FN-soldater. Ofte kunne UNPROFOR ikke hindre at humanitære konvoier ble tatt. FN-baser ble angrepet, og FN-personell ble tatt som gisler.

Hva gjorde så verdensorganisasjonen? FN tok kontroll over flyplassen i Sarajevo og sørget for humanitær hjelp til den beleirede byen, men var selv en del av beleiringen. I de nesten fire årene Sarajevo var beleiret (fra 5. april 1992 til 29. februar 1996), ble over $13000 \mathrm{drept}$ - over 5000 var sivile, derav 1600 barn.

FN innførte økonomiske sanksjoner mot Serbia og Montenegro, men uten innvirkning på krigen. FN vedtok flyforbud, men flere tusen brudd ble observert. Som med andre tiltak ble FN her en maktesløs tilskuer. I mai 1993 utpekte FN seks «sikre soner» (enklaver) med noen hundre fredsbevarende tropper, ute av stand til å forsvare dem. I juni 1993 vedtok Sikkerhetsrådet at flyangrep kunne benyttes, enten for å beskytte FN-tropper eller når "sikre soner» ble beskutt. Dette forble stort sett en papirbestemmelse. Generalsekretær Boutros-Ghali og UNPROFOR-kommandant general Michael Rose var imot maktbruk.

Det viktigste $\mathrm{FN}$ foretok seg, var å opprette et internasjonalt krigsforbrytertribunal for det tidligere Jugoslavia (ICTY). Dette fikk imidlertid ingen umiddelbar effekt på krigføringen. Domstolens rolle kom først lenge etter at krigen var over.

Etter krigen (1999) fikk FNs generalsekretær Kofi Annan utført en evaluering av FNs rolle. Den var drepende, våpenembargoen og mangel på maktbruk ble kritisert. Her er noen sitater fra Kofi Annans rapport:

Peacekeepers must never again be deployed into an environment in which there is no cease-fire or peace agreement. Peacekeepers must never again be told that they must use their peacekeeping tools - lightly armed soldiers in scattered positions - 
to impose the ill-defined wishes of the international community on one or another of the belligerents by military means. If the necessary resources are not provided and the necessary political, military and moral judgements are not made - the job simply cannot be done. (Annan, 1999, s. 107)

We were, with hindsight, wrong to declare repeatedly and publicly that we did not want to use air power against the Serbs except as a last resort and to accept the shelling of the safe areas as a daily occurrence ... (Annan, 1999, s. 104)

I Nederland ble det utgitt en omfattende rapport, Srebrenica Report, i 2002. Rapporten er kritisk til FNs manglende vilje til handling og drøfter de nederlandske styrkenes ansvar. Den nederlandske regjeringen gikk av som følge av kritikken.

\section{Kontaktgruppen}

I april 1994 ble den såkalte Kontaktgruppen opprettet (USA, Russland, Storbritannia, Tyskland og Frankrike). I siste fase av krigen i Bosnia overtok Kontaktgruppen fredsforhandlernes rolle, men gruppen var splittet. Amerikanerne gikk inn for «lift and strike», noe de europeiske stormaktene ikke støttet. Russland hadde dessuten sin egen agenda på Balkan. Kontaktgruppen vedtok at ved en fredsløsning skulle serberne ha 49 prosent av territoriet. Det var jo sjenerøst, med tanke på at serberne hadde utgjort 31 prosent av befolkningen, hadde startet krigen og var skyld i massive krigsforbrytelser. Likevel avslo serberne Kontaktgruppens fredsplan. Planen lovet ikke serberne autonomi, og siden det ikke var troverdige trusler om maktbruk, kunne serberne fortsatt håpe på større gevinst.

\section{Natos rolle}

Bare i svært begrenset grad ble Nato brukt for å overholde FNs vedtak i Bosnia. Krigsskip patruljerte adriaterhavskysten for å hindre brudd på våpenembargoen, og Nato skulle overvåke flyforbudet. Da serberne angrep den «sikre sonen» Goražde, foretok Nato begrensede flyangrep i april 1994, men for å hindre det tok serberne $200 \mathrm{FN}$-personell til fange og brukte dem som levende skjold mot luftangrep. I mai 1995 foretok Nato flyangrep mot serbiske stillinger rundt Sarajevo. Det førte til at $400 \mathrm{FN}$-personell ble tatt som gisler og brukt som levende skjold. Disse halvhjertede Nato-innsatsene overbeviste serberne om at de ikke hadde noe å frykte fra Nato. General Mladić og hans politiske leder Radovan Karadžić var ikke redde for internasjonale reaksjoner da de bestemte seg for å innta den «sikre sonen» Srebrenica. De hadde dessuten støtte fra Serbia (president Milošević).

\section{Massakren i Srebrenica}

I juli 1995 var FN handlingslammet og hadde mistet mye prestisje. Det var åpenbart at UNPROFORs oppgave primært var å beskytte FN-ansatte. Manglende innsats fra det 
internasjonale samfunnet ga de ekstreme nasjonalistene fritt leide, de var overbevist om at de kunne giøre hva som helst uten noen gang å bli stilt til ansvar. Ganske riktig, FN gjorde ikke noe for å stanse den serbiske fremrykkingen mot Srebrenica, der det oppholdt seg 40 000. Tre dager før angrepet spiste kommandanten for FN-styrkene, den franske generalen Bernard Janvier, grillet lam og spedgris med general Mladić.

Angrepet startet den 6 . juli med stridsvogner og tungt artilleri. Dagen etter hadde Carl Bildt et møte i Beograd med president Milošević og general Mladić om fredsplaner! Den nederlandske bataljonen (oberst Karremans) fremmet en rekke anmodninger om flystøtte, og Nato-fly var parate, men det ble avslått av general Janvier. Angrepet fortsatte til den 11 . juli, da byen falt. De nederlandske styrkene kunne bare være tilskuere. Et par hundre dårlig utrustede nederlandske soldater var ikke noe hinder for serberne, de behøvde ikke løsne et skudd, tretti nederlendere ble tatt som gisler. Kofi Annan innrømmer i sin rapport at $\mathrm{FN}$ var totalt «på jordet»:

The day before Srebrenica fell we reported that the Serbs were not attacking when they were. We reported that the Bosnians had fired on an Unprofor blocking position when it was the Serbs. We failed to mention urgent requests for air power.

(Annan, 1999, s. 106)

General Mladić skilte menn og gutter fra kvinner og barn, til dels med hjelp fra FN-personell. De følgende dagene ble omkring 8000 likvidert. Likene ble forsøkt skjult i massegraver. Men serberne forregnet seg da de trodde at massakrene ville forbli ukjent for verdenssamfunnet.

Den første som snappet opp informasjon om massakren i Srebrenica, var den norske antropologen Tone Bringa, som arbeidet for UNPROFOR i Zagreb. 22. juli fløy hun til Tuzla, der hun fikk kontakt med en som hadde overlevd massakren. Hun rapporterte til den amerikanske ambassadøren i Zagreb, Peter Galbraith, som underrettet Washington. Yasushi Akashi, FNs spesialutsending i det tidligere Jugoslavia, fikk rapporten 30. juli, og USAs FN-ambassadør Madeleine Albright la rapporten med flyfoto frem for FNs sikkerhetsråd.

Verdenssamfunnet kunne ikke lenger betrakte overgrepene uten å reagere. I tillegg til Srebrenica-massakren var det andre begivenheter som utløste politisk og militær handlekraft. 25. juli tok serberne den "sikre» enklaven Žepa og truet den «sikre» enklaven Goražde. Kroatias offensiv, Operasjon Storm 4.-8. august, jaget serberne ut av Krajina, og kroatene og bosnjakene begynte en offensiv mot serbiske styrker i Vest-Bosnia. Så kom det serbiske granatangrepet mot markedsplassen i Sarajevo 28. august, som drepte 37 personer og såret mange. Vestlige politikere gikk nå inn for maktbruk, og kommandanten for FN-styrkene, briten Rupert Smith, støttet dette, i motsetning til sine forgjengere. FN overlot i realiteten styringen til Nato.

30. august begynte operasjonen Deliberate Force. Nato-fly bombet serbiske mål, og britiske og franske styrker (Rapid Reaction Force) på Igman-fjellet angrep serbiske stillinger rundt Sarajevo. Etter en mislykket forhandlingspause på fire dager ble angrepene gjenopptatt 5 . september. I tillegg til flybombing ble også krysserraketter 


\section{Svein Mønnesland}

brukt. Luftangrepene ble avsluttet 14 . september. General Mladić ble tvunget til å trekke tunge våpen fra beleiringen av Sarajevo. Det viste seg at en begrenset militær aksjon var nok til å få slutt på krigen. De bosnisk-serbiske styrkene var svake. Dette sto i motsetning til det som var blitt hevdet av mange, at en militær løsning ikke var mulig.

\section{Norske holdninger}

Uansett hvilke overgrep som ble begått, var de ansvarlige i FN-systemet imot maktbruk. Etter Srebrenica uttalte FNs generalsekretær Boutros-Ghali: «In spite of the aggression, negotiation is for the time being the only way to find a solution.» Dette var i motsetning til presidentene Chirac og Clinton, som reagerte sterkt og forlangte handling.

I Norge og også internasjonalt var Thorvald Stoltenberg en sterk motstander av maktbruk. Under hele krigen i Bosnia argumenterte han for at det var umulig å bruke militær makt mot serberne, for eksempel:

Fredsmekler Thorvald Stoltenberg advarte mot bombing, og kjempet for en politisk løsning, da EUs utenriksministrer i går diskuterte det bosniske blodbadet etter massakrene i helgen. - Hvis vi begynner å bombe stillinger rundt Sarajevo, er vi inne i en ond sirkel, sa Thorvald Stoltenberg etter møtet i Brussel. (Dagbladet, 8. februar 1994)

Han argumentere gierne med at det ville kreves flere hundre tusen bakkestyrker, og at bombing i Bosnia kunne føre til krig på hele Balkan og enda videre i Europa. Også fredsmekler Kai Eide argumenterte på samme i artikkelen «Bomber ingen løsning»:

I disse dager er Eide mest opptatt av at man må være klar over at det er umulig å bombe seg frem til en løsning på den mer enn to år lange krigen i Bosnia. «Jeg er ikke overbevist om at alle som snakker om økt maktbruk fra FNs side, vet hva de snakker om. Hvis vi ikke er varsomme og ser hvor komplisert situasjonen er, kan vi oppnå det motsatte av hensikten.» (Aftenposten, 20. april 1994)

Oberst Hagrup Haukland var sjef for FN-styrkene i den delen av Bosnia der Srebrenica ligger. Da det serbiske angrepet kom, var han på ferie i Norge. Etter at Natos flyangrep var i gang, uttaler han at Natos aksjoner mot serbiske mål kan skade fredsprosessen, man må ikke ta parti mot de serbiske styrkene (Morgenbladet, 15. september 1995).

I juli 1995, etter Srebrenica-massakren, henvendte aksjonsgruppen La Bosnia leve seg til de politiske partiene for å få deres syn på konflikten. Partileder Thorbjørn Jagland svarte, på stortingsgruppens offisielle brevpapir:

Etter Arbeiderpartiets oppfatning er konflikten i Bosnia og det tidligere Jugoslavia generelt meget komplisert. Situasjonen er dramatisk og tragisk, og det er ikke vanskelig å slutte seg til de som sier at den er utålelig. Vi kan imidlertid ikke se at det finnes noen enkel strategi som, om det internasjonale samfunnet stiller seg bak 
den, ville forbedre situasjonen. Mange av de løsningene som er foreslått, i beste hensikt, vil i stedet kunne føre til en spredning eller utvidelse av krigen

Arbeiderpartiet mener at varige løsninger bare kan finnes ved forhandlingsbordet, derfor støtter vi forhandlingsprosessene og fredsmeklernes innsats. Selv om FN har møtt store vanskeligheter, er FN-styrkenes innsats likevel viktig. Vi ønsker å beholde FNs nærvær i området så lenge som mulig fordi dette er avgjørende for det humanitære hjelpearbeidet. Derfor har også Norges engasjement i det tidligere Jugoslavia vært konsentrert om bidrag til humanitær hjelpeinnsats og deltakelse i FNs operasjoner ved UNPROFOR.

Arbeiderpartiet mener videre at FNs og NATOs upartiskhet må videreføres. Det ville ikke være et positivt bidrag til løsningen av konflikten om det internasjonale samfunnet skulle gå inn som en krigførende part.Vi støtter heller ikke en opphevelse av våpenembargoen. (Jagland, 1995)

Dette brevet undertegnet Jagland 16. august. 14 dager senere startet Natos flybombing av serbiske stillinger.

Helt annerledes var politikken til Kristelig Folkeparti. 8. august svarte partileder Valgerd Svarstad Haugland, på stortingsgruppens offisielle brevpapir:

Kristelig folkeparti mener at Bosnia må bevares som en enhetlig, multikulturell, multinasjonal demokratisk stat med like rettigheter for alle befolkningsgruppene.

FN burde i langt større grad ha benyttet den fullmakten som er gitt for nødvendige tiltak for å sikre forannevnte målsetting for Bosnia. Verdenssamfunnet har på en uakseptabel måte latt de serbiske opprørerne krenke sivilbefolkningen og den bosniske regjeringen. $\mathrm{KrF}$ mener at NATO burde vært benyttet til målrettede bombeangrep av serbiske stillinger, for å redusere disses slagkraft og markere at man stiller makt bak kravene. Det var helt uakseptabelt når serberne endog gjorde overgrep mot de FN-beskyttede sikre soner.

Vi er redde for at den opptrapping av konflikten vi nå har sett i senere tid også er en konsekvens av at $\mathrm{FN}$ tidligere har vist handlingslammelse og manglende vilje til å følge opp egne vedtak. (Haugland, 1995)

Kristelig folkeparti var dermed helt på linje med det som ble det internasjonale samfunnets reaksjon på Srebrenica-massakren. At Arbeiderpartiet ikke var det, tjener ikke partiet til ære.

\section{Konklusjon}

Verdenssamfunnets svik i Bosnia-Hercegovina er blitt sammenlignet med München-avtalen i 1938, naivitet og manglende handlekraft mot destruktive krefter. Dette antyder også Kofi Annan (1999) i sin rapport: «These negotiations amounted to appeasement."

Det var nok av advarende røster som så faren ved den politikken som ble ført. Allerede i 1993 dokumenterte den norske lagdommeren Hanne Sophie Greve at den etniske rensingen i Prijedor kommune nordvest i Bosnia kunne karakteriseres som folkemord. Hun var medlem av FNs ekspertkomité, som skulle undersøke forholdene i Bosnia for å forberede et mulig krigsforbrytertribunal. Greves detaljerte 


\section{Svein Mønnesland}

rapport var en viktig grunn til at Sikkerhetsrådet bestemte seg for å opprette domstolen. Det som foregikk i Prijedor i 1992, pekte frem mot at noe lignende og enda verre kunne skje. Srebrenica-massakren kom ikke uventet på dem som hadde studert Hanne Sophie Greves rapport.

Tidlig i 1993 utga en bosnisk flyktning i Norge, Rezak Hukanović, en bok om sine opplevelser i en av «dødsleirene» i Prijedor. Boken kom ut på norsk, bosnisk og engelsk og nådde dermed et stort publikum. Bak på omslaget står det: «Vi har ikke lov til å si: - Vi visste det ikke ..."

Mange vestlige politikere og aktører i fredsprosessene lot som de ikke visste, til tross for påtrykk fra opinionen. I september 1993 undertegnet hundre personer en appell til president Clinton om å lede en militær intervensjon, blant andre tidligere utenriksminister George Schultz, statsminister Margaret Thatcher og kjente navn fra kultur, vitenskap og politikk, blant andre Elie Wiesel, Susan Sontag og også serbiske intellektuelle, som advokaten Srdja Popović og forfatteren Mirko Kovač. Men Clinton nølte.

For mange, ikke minst i Norge, var det vanskelig å ta inn over seg at FN ikke fungerte som et positivt bidrag til å løse konflikten. Det som kunne se ut om noe positivt, at FN påla seg samme restriksjoner som Røde Kors, absolutt nøytralitet og upartiskhet, ble i virkeligheten korrumperende for verdensorganisasjonen. I stedet for å være uttrykk for verdenssamfunnets rettsoppfatning ble FN avhengig av å blidgiøre krigsforbrytere. Dermed måtte virkeligheten omskrives, krigen tolkes som en konflikt mellom likeverdige parter, alle var like skyldige. Det måtte skapes tvil om det var serberne som skjøt granater mot markedsplassen i Sarajevo - kanskje det var bosnjakene selv som drepte sine egne? At FN fratok et medlemsland retten til å forsvare seg, ble omskrevet med at dette var for å skape fred.

Vestlige politikere handlet ut fra ulike motiver. For noen var det sikreste ikke å gjøre noe. For andre var statens interesser involvert på den ene eller andre måten i det jugoslaviske dramaet. Det er ikke bare i eks-Jugoslavia at historien forties og omskrives. Mange har ikke tatt inn over seg ansvaret. Derfor er det så befriende å lytte til Kofi Annan:

The cardinal lesson of Srebrenica is that a deliberate and systematic attempt to terrorize, expel or murder an entire people must be met decisively with all necessary means, and with the political will to carry the policy through.

Through error, misjudgement and an inability to recognize the scope of the evil confronting us, we failed to do our part to save the people of Srebrenica from the Serb campaign of mass murder. The tragedy of Srebrenica will haunt us forever. (Annan, 1999, s. 108)

Noe lignende uttalte FNs høykommissær for flyktninger, Al Hussein, i en tale til Sikkerhetsrådet i 2015:

Srebrenica was a catastrophe for its inhabitants and refugees huddled there on 11 July 1995, and also for the people of Bosnia and Herzegovina and for the UN. 
It is a trauma from which we could still learn, with great remorse. For many of us who served with the UN in the former Yugoslavia, Srebrenica will remain for many years the heart that breaks daily. (Al Hussein, 2015)

\section{Om forfatteren}

Svein Mønnesland, professor emeritus i slaviske språk ved Universitetet i Oslo. Har skrevet mye om Balkan og jugoslavisk kulturhistorie. Medlem av Det Norske Videnskaps-Akademi og Vitenskapsakademiet i Bosnia-Hercegovina.

\section{Litteratur}

Det finnes en svært omfattende litteratur om krigene i det tidligere Jugoslavia, se for eksempel bibliografien i Resić (2018). Et enormt materiale er samlet inn av Det internasjonale tribunalet for det tidligere Jugoslavia. Her er noen få titler.

Al Hussein, Z. R. (2015). Remarks by the High Commissioner to the Security Council meeting on Bosnia and Herzegovina (Srebrenica). Hentet 15. mars 2020 fra https://www.ohchr.org/EN/NewsEvents/Pages/ DisplayNews.aspx?NewsID=16218\&LangID=E\#navigation)

Annan, K. A. (1999). Report of the Secretary-General pursuant to General Assembly resolution 53/35. The fall of Srebrenica. New York: United Nations publication. Hentet 15. mars 2020 fra https://undocs. org/A/54/549

Burg, S. L. \& Shoup, P. S. (1999). The war in Bosnia-Herzegovina. Ethnic conflict and international intervention. New York: M. E. Sharpe.

Finlan, A. (2004). The collapse of Yugoslavia 1991-1999. Oxford, England: Osprey Publishing.

Haugland, V. S. (1995, 8. august). Brev til La Bosnia leve, upublisert.

Hoare, M. A. (2007) The history of Bosnia. From the Middle Ages to the present day. London, England: Saqi Books.

Holbrooke, R. (1998). To end a war. New York: Random House.

Jagland, T. (1995, 16. august). Brev til La Bosnia leve, upublisert.

Løken, K. (1994, 20. april). Bomber er ingen løsning. Aftenposten, s. 13.

Mønnesland, S. (2006). Før Fugoslavia og etter (5. utg.). Oslo: Sypress Forlag.

Nilsen, K. A. (1996). Europas svik. Et oppgjør med vestlig unnfallenhet i Bosnia. Oslo: Spartacus.

NIOD Institute for War, Holocaust and Genocide Studies. (2002). Srebrenica. Reconstruction, background, consequences and analyses of the fall of a 'safe' area. Amsterdam: NIOD Institute for War, Holocaust and Genocide Studies. Hentet 15. mars fra https://www.niod.nl/en/srebrenica-report

Owen, D. (1995). Balkan odyssey. London: Victor Gollancz.

Ramet, S. (2006). The three Yugoslavias. State-building and legitimation, 1918-2005. Bloomington, IN: Indiana University Press.

Resić, S. (2018). Fugoslaviens undergång. Krigen. Freden. Framtiden. Lund: Historiska Media.

Rohde, D. (2012). Endgame. The betrayal and fall of Srebrenica: Europe's worst massacre since World War II. London, England: Penguin Books.

Strand, M. (1994, 8. februar). Thorvald sier nei til bomber. Dagbladet, s. 18.

Woodward, S. L. (1995) Balkan tragedy. Washington, DC: The Brookings Institution.

Zimmermann, W. (1999). Origins of a catastrophe (2. utg.). New York: Times Books.

\section{Abstract in English \\ Srebrenica 25 Years After - How Could the Genocide Happen?}

The genocide in Srebrenica in July 1995 shocked the world. Since 1992, when the war broke out, Bosnia and Herzegovina had been supervised by the international community. The article discusses why genocide and crimes against 
humanity could happen without being stopped. Focus is on the role of the relevant international participants, the UN, the EU, NATO and the great powers. Why was there a strong opposition against use of force? It was partly due to weak understanding of what was going on, a concept of the Balkans as a region of inherent centuries-old hatred. Some Western states had their own interests in the region. For Western politicians the easiest way was to do nothing. The UN sent peacekeepers to a country at war, which turned out to be a catastrophe for the peacekeepers and for the prestige of the UN. Measures like Security Council resolutions, economic sanctions, arms embargo, safe havens and no-fly zones did not work. Many Norwegian politicians were strongly opposed to military intervention. The Serbian army was too strong, a military solution was not possible. This turned out to be wrong. The genocide in Srebrenica triggered the use of force by the UN and NATO in September 1995. A limited military action was enough to end the war, after which real peace talks could start.

Keywords: Bosnia and Herzegovina - United Nations • NATO • EU • military intervention 